\title{
Species-Specific Differences in Expression of G-Protein-Coupled Receptor Kinase (GRK) 7 and GRK1 in Mammalian Cone Photoreceptor Cells: Implications for Cone Cell Phototransduction
}

\author{
Ellen R. Weiss, ${ }^{1,2}$ Melissa H. Ducceschi, ${ }^{1}$ Thierry J. Horner, ${ }^{1}$ Aimin Li, ${ }^{3}$ Cheryl M. Craft, ${ }^{3}$ and Shoji Osawa ${ }^{1}$ \\ ${ }^{1}$ Department of Cell and Developmental Biology, ${ }^{2}$ Lineberger Comprehensive Cancer Center, The University of North \\ Carolina at Chapel Hill, Chapel Hill, North Carolina 27599-7090, and ${ }^{3}$ Mary D. Allen Laboratory for Vision Research, and \\ Department of Cell and Neurobiology, Doheny Eye Institute, Keck School of Medicine, The University of Southern \\ California, Los Angeles, California 90033
}

Desensitization plays an important role in the rapid termination of G-protein signaling pathways. This process, which involves phosphorylation by a G-protein-coupled receptor kinase (GRK) followed by arrestin binding, has been studied extensively in the rod photoreceptor cell of the mammalian retina. In contrast, less is known regarding desensitization in cone photoreceptor cells, which occurs more rapidly than in rod cells. Recently, our laboratory has cloned a novel GRK family member, GRK7, from the retina of a cone-dominant mammal, the 13-lined ground squirrel. Here we report the cloning of GRK7 from rod-dominant pig and human retinas, suggesting that this kinase plays a role in human visual signaling. Because GRK1 (rhodopsin kinase), the GRK that mediates rhodopsin desensitization in the rod cell, is reportedly expressed in both rods and cones, a detailed comparison of the localization of the two kinases is a necessary

Rapid termination of G-protein signaling is critical for acute regulation of neuronal pathways initiated by G-protein-coupled receptors (GPCRs). This process is partly regulated by desensitization, a series of events involving phosphorylation of the ligand-activated GPCR by a G-protein-coupled receptor kinase (GRK) followed by the binding of a member of the arrestin family (Krupnick and Benovic, 1998). As a result, the receptor is no longer sensitive to ligand. Defects in desensitization have been implicated in several pathological conditions, including drug addiction, hypertension, and retinal disease (Pitcher et al., 1998).

Analysis of the phosphorylation of rhodopsin, the light receptor of the rod photoreceptor cell, by rhodopsin kinase (GRK1)

Received June 11, 2001; revised Aug. 2, 2001; accepted Aug. 22, 2001.

This work was supported by Grants EY12224 (S.O.), GM43582 (E.R.W.), EY00395 (C.M.C.), and EY03042 (Core Vision Research Center grant, Doheny Eye Institute) from National Institutes of Health. C.M.C. is the Mary D. Allen Professor for Vision Research. We thank Drs. Paul Hargrave, Jeremy Nathans, Krzysztof Palczewski, Agoston Szél, and Timothy Kraft for valuable reagents. We also thank Dr. Timothy Johnson, Dr. Christian Newcomer, Connie Engle, Chris Seagle, Meri Winchester, and coworkers in the Departments of Cardiology and Surgery at The University of North Carolina at Chapel Hill for help in obtaining mammalian eyes. Human eyes were obtained from the Alzheimer's Disease Center, Neuropathology Core, the Keck School of Medicine of the University of Southern California, funded by National Institute of Aging Grant P59-AG051542 (Carol Miller, M.D.). We also thank Drs. Fulton Wong and You-Wei Peng for helpful discussions regarding this manuscript.

Correspondence should be addressed to Dr. Shoji Osawa, Department of Cell and Developmental Biology, The University of North Carolina at Chapel Hill, CB\# 7090, 108 Taylor Hall, Chapel Hill, NC 27599-7090. E-mail: shoosawa@ med.unc.edu.

Copyright $\odot 2001$ Society for Neuroscience $0270-6474 / 01 / 219175-10 \$ 15.00 / 0$ step toward determining their potential roles in cone visual signaling. Immunocytochemical analysis using antibodies selective for these two GRKs unexpectedly demonstrated species-specific differences in GRK7 and GRK1 expression in cones. In pigs and dogs, cones express only GRK7, whereas in mice and rats, we detected only GRK1 in cones. These results suggest that either GRK7 or GRK1 may participate in cone opsin desensitization, depending on the expression pattern of the kinases in different species. In contrast, GRK7 and GRK1 are coexpressed in monkey and human cones, suggesting that coordinate regulation of desensitization by both kinases may occur in primates.

Key words: cone; desensitization; GRK1; GRK7; kinase; photoreceptor; retina; rod; vision

and the subsequent step of arrestin binding have led to a basic understanding of the mechanism of GPCR desensitization (Fain et al., 2001) and provided insight into its role in visual signaling in rod cells. In contrast, the process of desensitization is not well characterized in cone photoreceptor cells because these cells comprise $<15 \%$ of the photoreceptor cell population in most mammalian retinas. Cones are less sensitive to light than rods and recover more rapidly after light exposure (Baylor, 1987; Yau, 1994), suggesting that the mechanism of desensitization may be different in rods and cones. Although isoforms of many rod cell proteins implicated in visual signaling are found in cones and appear to have similar functions, a GRK that phosphorylates the cone opsins in the retina has not been identified. A novel GRK, GRK7, was recently cloned by our laboratory from the retinas of a cone-dominant mammal, the 13-lined ground squirrel (Weiss et al., 1998), and from fish, reptile, and amphibian retinas (Hisatomi et al., 1998). GRK7 phosphorylates rhodopsin in vitro in a lightdependent manner (Weiss et al., 1998), indicating that it is a GRK family member. Interestingly, several laboratories have reported that the rod cell GRK, GRK1, is also expressed in cones (Zhao et al., 1998; Lyubarsky et al., 2000; Sears et al., 2000), suggesting that GRK1 may mediate opsin desensitization in cones. In addition, knock-out mice lacking GRK1 show defects in cone cell recovery after light exposure (Lyubarsky et al., 2000). A comprehensive, comparative analysis of GRK7 and GRK1 expression is a critical step in defining the functions of these two GRKs in the retina.

In the present study, we report the cloning of GRK7 from 
rod-dominant human and pig retinas and have analyzed the expression patterns of GRK7 and GRK1 in rod- and cone-dominant retinas. We detected GRK7 in the cones of all species that we examined except mice and rats. GRK1 is expressed in cones in these two species but was not detected in cones in dog and pig retinas. In contrast, GRK7 and GRK1 are coexpressed in the inner and outer segments of monkey and human cones. Therefore, the kinase that participates in cone opsin desensitization may differ, depending on the expression pattern, in different species. In primates, because GRK7 and GRK1 are coexpressed in cones, they both have the potential to play a role in cone opsin desensitization. These results have important implications for understanding the effects of previously described GRK1 mutations on photoreceptor cell desensitization in inherited retinal diseases.

\section{MATERIALS AND METHODS}

\section{Cloning of pig and human GRK7}

Pig and human GRK7 were cloned from retinal RNA using a Rapid Amplification of cDNA Ends (RACE) strategy. The sequence of the full-length pig GRK7 cDNA was obtained by extending the $5^{\prime}$ and $3^{\prime}$ nucleotide sequences with primers anchored within a cDNA fragment (345 bp) of pig GRK7 cloned previously by our laboratory (Weiss et al., 1998). Advantaq polymerase and the SMART RACE cDNA Amplification kit from Clontech (Palo Alto, CA) and the 3' R ACE System kit from Life Technologies (Rockville, MD) were used for this purpose. The primers UPM (Clontech) and 5'-GTGAAGCTTTGGTGTTGGAAT CTGACCTCTTCTTTCAGTGTTC-3' (reverse complement of the pig cDNA nucleotide sequence 1321-1363) were used for extension of the $5^{\prime}$ end of the pig cDNA. The primers 5'-AGCATTTATGAAATGG TCGCTGGACGAACACC-3' (nucleotides 1242-1273 of the pig cDNA sequence) and AUAP (Life Technologies) were used for extension of the $3^{\prime}$ end of the pig cDNA.

To clone the human GRK7 cDNA, a 172-base fragment was amplified from human retina Marathon-Ready cDNA (Clontech) by PCR using the primers, 5'-AGCATTTATGAAATGGTCGCTGGACGAACACC-3' and 5'-GCTCTGGTGTCTTAGCCAAGAAGAGTCTGC-3', corresponding to the pig GRK7 cDNA sequence (nucleotides 1242-1273 and the reverse complement of nucleotides $1384-1413$, respectively). The $5^{\prime}$ sequence was extended using AP1 (Clontech) and 5'-GCTTCC TCTGTGAAGTTATCATGCTGGAATTTGACCTCG-3' (the reverse complement of nucleotides 1314-1352 of the human GRK7 cDNA sequence). For $3^{\prime}$ extension, 5'-GGAACCAATGGTTACATGGCTCCT GAGATCCTAATGG-3' (nucleotides 1138-1174 of the human GRK7 cDNA sequence) and AP1 were used. The cDNA sequences for human and pig GRK7 were submitted to GenBank and given the accession numbers AF282269 and AF282270, respectively.

\section{Chromosomal localization of GRK7}

Two primers, 5'-AAGCCCTCGGACTGCGACAGCAAAGAGCTG-3' (nucleotides 145-174 of the human GRK7 cDNA sequence) and $5^{\prime}$ GCTCCCAGTTCTGCACGTCCTCTAGGAAGG-3' (reverse complement of the human GRK7 cDNA nucleotide sequence 338-367) were submitted to Research Genetics, Inc. (Huntsville, AL) for mapping the chromosomal location of human GRK7 by radiation hybrid analysis.

\section{Antibodies}

Antibodies were generated against synthetic peptides LNDPNRPAGCGEGNS (amino acids 530-544) and LNDPNRPSGDGKGDS (amino acids 525-539), corresponding to a region near the $\mathrm{C}$ terminus of pig and 13-lined ground squirrel GRK7, respectively (see Fig. 1). There is little homology between GRK7 and other GRKs in this region. The synthetic peptides were conjugated to KLH through a cysteine residue added to the $\mathrm{N}$ terminus of each peptide. The antibodies were generated in rabbits and affinity purified against peptide conjugated to bovine serum albumin (BSA) (Quality Controlled Biochemicals Division, Biosource International, Hopkinton, MA).

Several antibodies that recognize GRK1 were tested for crossreactivity with GRK7. D11, a monoclonal antibody that recognizes an N-terminal fragment of human GRK1 (Zhao et al., 1998), was found to be specific for GRK1 by Western blot analysis (see Fig. 2) and immunocytochemistry (data not shown). Therefore D11 was used for our studies.
This antibody was kindly supplied by Dr. Krzysztof Palczewski (University of Washington, Seattle, WA). Rabbit polyclonal antibodies against human red/green and blue opsins were supplied by Dr. Jeremy Nathans (The Johns Hopkins School of Medicine, Baltimore, MD). The antirhodopsin monoclonal antibody, R2-15N, was a gift from Dr. Paul Hargrave (University of Florida, Gainesville, FL). The monoclonal antibodies COS-1 and OS-2, which recognize the red/green and blue opsins, respectively (Szél et al., 1988), were a generous gift from Dr. Agoston Szél (Semmelweis University, Budapest, Hungary).

\section{Western blot analysis of recombinant GRKs and mammalian retina extracts}

Histidine-tagged (6xhistidine) GRK7 and GRK1 cDNAs were ligated to pcDNA1/Amp (Invitrogen, Carlsbad, CA) for expression in human embryonic kidney-293 (HEK-293) cells, as described previously (Weiss et al., 1998). Three days after transfection, the cells were solubilized in buffer containing $20 \mathrm{~mm}$ HEPES, pH 7.2, $250 \mathrm{~mm} \mathrm{NaCl}, 2$ mM EDTA, $0.02 \%$ Triton X-100, $1 \mathrm{~mm}$ DTT, $0.5 \mathrm{M} \mathrm{NaF}, 20 \mu \mathrm{g} / \mu \mathrm{l}$ leupeptin, and 20 $\mu \mathrm{g} / \mu \mathrm{l}$ benzamidine. After centrif ugation, the lysates were diluted to $50 \%$ with glycerol and stored at $-20^{\circ} \mathrm{C}$. Protein concentrations were determined using the Bio-Rad DC assay kit (Bio-Rad, Hercules, CA). All of the GRK7 and GRK1 proteins expressed in HEK-293 cells were shown to be functional, on the basis of their ability to phosphorylate rhodopsin in a light-dependent manner (data not shown) (Weiss et al., 1998). Retinas were solubilized in buffer containing $6.25 \mathrm{~mm}$ Tris-HCl, $\mathrm{pH} 6.8$, $2 \%$ SDS, and $10 \%$ glycerol. Twenty micrograms of HEK-293 cell extracts, $20 \mu \mathrm{g}$ of 13-lined ground squirrel (Spermophilus tridecemlineatus), eastern chipmunk (Tamias striatus), pig, mouse, and bovine retina extracts, or $40 \mu \mathrm{g}$ of monkey or dog retina extracts was separated by SDS-PAGE and transferred electrophoretically to polyvinylidene difluoride membrane. Membranes were immunoblotted with anti-ground squirrel GRK7, anti-pig GRK7, or anti-GRK1 (D11) at 1:2000, 1:4000, and 1:10,000 dilutions, respectively. Anti-mouse or anti-rabbit alkaline phosphatase secondary antibodies (Cell Signaling Technology, Beverly, MA) were used at a dilution of 1:2000.

\section{Immunocytochemistry}

Ground squirrel, pig, dog, monkey, and mouse retinas. All animals used in these studies were treated according to the Association for Research in Vision and Ophthalmology Statement for the Use of Animals in Ophthalmic and Vision Research. Ground squirrels were obtained from TLS Research (Bartlett, IL). Pig, dog, and monkey eyes were obtained from the Departments of Cardiology and Surgery at the University of North Carolina at Chapel Hill. Mice and rats were obtained from Charles River Laboratories (Wilmington, MA) and Zivic-Miller (Pittsburgh, PA), respectively. Eyes from euthanized animals were fixed in $4 \%$ paraformaldehyde in PBS for $\sim 20 \mathrm{hr}$ at $4^{\circ} \mathrm{C}$. The eyes were cryoprotected sequentially in 10,20 , and $30 \%$ sucrose, frozen in O.C.T. Compound or homogenized chicken liver, and then sectioned at $10 \mu \mathrm{m}$. Sections were post-fixed for $20 \mathrm{~min}$ with $4 \%$ paraformaldehyde in PBS at room temperature and rinsed four times with PBS. They were permeabilized with $0.2 \%$ Triton X-100 in PBS for $10 \mathrm{~min}$, rinsed three times for 5 min each in Tris-buffered saline (TBS), and blocked for $1 \mathrm{hr}$ at room temperature in TBS containing 5\% normal goat serum, 5\% BSA, and $0.1 \%$ Triton $\mathrm{X}-100$. The samples were then incubated with primary antibodies at appropriate dilutions in TBS containing 5\% BSA and $0.1 \%$ Triton X-100 overnight in a humidified chamber at $4^{\circ} \mathrm{C}$. The sections were rinsed three times with TBS containing 0.1\% Triton X-100 (TBST), once with TBS, then incubated in Oregon Green-conjugated goat anti-mouse secondary antibody (1:2000 dilution) or Texas Red-conjugated goat anti-rabbit (1:2000 dilution; Molecular Probes, Eugene, OR) in TBS containing 5\% BSA and $0.1 \%$ Triton $\mathrm{X}-100$ for $2 \mathrm{hr}$ at $37^{\circ} \mathrm{C}$. Sections were again rinsed three times with TBST and once with TBS, then coverslipped with Gel/Mount Aqueous Mounting Media (Fisher Scientific, Houston, TX) for visualization using a Nikon E400 fluorescence microscope. Images were recorded with a Spot-RT camera. For some experiments, competing peptides were preincubated with antibody overnight at $4^{\circ} \mathrm{C}$ at a 500 -fold molar excess, then centrifuged to remove antibody-antigen complexes. The supernatant was incubated with sections as described above.

Human retinas. Human eyes were obtained from the Alzheimer's Disease Center at the Keck School of Medicine of the University of Southern California and the A. Ray Irvine, Jr. Ophthalmic Pathology Laboratory, Doheny Eye Institute, the University of Southern California (IRB\# 845011). Eyes with a postmortem time of 3-8 hr were fixed in either $10 \%$ buffered formaldehyde or $4 \%$ paraformaldehyde and pro- 
cessed as described previously (Zhu and Craft, 2000; Zhang et al., 2001). The eyes were dehydrated overnight using an automated Shandon Citadel 2000 dehydrator, embedded, oriented sagittally for $6 \mu \mathrm{m}$ sections through the optic nerve with a JUNGRM2035 macrotome (Leica, Foster City, CA), and subjected to immunohistochemical staining.

Immunocytochemistry was performed as described (Zhu and Craft, 2000), with a few modifications. After deparaffination and hydration through graded alcohols, the sections were heated in $0.01 \%$ sodium citrate buffer, $\mathrm{pH}$ 6.0, for $20 \mathrm{~min}$ for antigen retrieval. After cooling to room temperature and rinsing with $\mathrm{PBS}$, they were blocked with $3 \%$ $\mathrm{H}_{2} \mathrm{O}_{2}$ and $5 \%$ normal goat serum before incubation with anti-ground squirrel GRK7 peptide antibody (1:500) overnight at $4^{\circ} \mathrm{C}$. After the washing steps, the sections were reacted for $30 \mathrm{~min}$ at room temperature with biotinylated anti-rabbit IgG and washed for $50 \mathrm{~min}$ at room temperature with Vectastain Elite ABC Reagent (Vector Laboratories, Burlingame, CA). After washing, the sections were reacted with freshly prepared peroxidase substrate (diaminobenzidine tetrahydrochloride, Vector Laboratories) for at least $1 \mathrm{~min}$, rinsed with water, dehydrated through graded alcohols, and cleared with xylene. For controls, the primary antibody incubation was omitted (data not shown). The specificity of the antibody was confirmed by preabsorption with synthetic peptides corresponding to amino acids 525-539 of ground squirrel GRK7 or to amino acids 530-544 of human GRK7 (see Fig. 1). A 500-fold molar excess of peptide was mixed with antibody for $2 \mathrm{hr}$ at $4^{\circ} \mathrm{C}$ before incubation with sections. Examination and photography were performed using a Nikon light microscope and a Spot digital camera.

\section{RESULTS}

\section{Cloning of GRK7 from pig and human retinas}

To characterize the expression of GRK7 in rod-dominant mammals, the cDNA was isolated from human and pig retina cDNA libraries. The human and pig GRK7 cDNAs are 3186 and $2453 \mathrm{bp}$ in length, respectively, including a coding region of 1659 bases corresponding to a predicted 553 amino-acid polypeptide. Radiation hybrid analysis links the human gene to the marker D3S1309 located at 3q23 in the human genome. This locus is not presently associated with any inherited retinal diseases. A BLAST search of the recently released working draft of the Human Genome Project (http://www.ncbi.nlm.nih.gov/genome/guide/human/) also places GRK7 on chromosome 3. An analysis of the intron/exon organization using the information from the Human Genome Project shows that the GRK7 gene has 3 introns, fewer than any other GRK examined [GRK1, 6 introns (Khani et al., 1996); GRK2, 20 introns (Penn and Benovic, 1994); GRK4/5/6, 15 introns (Premont et al., 1996, 1999)]. One of the intron/exon boundaries in GRK7 between Glu-204 and Val-205 is at the same position as in the GRK4/5/6 family (Premont et al., 1999), within the highly conserved subdomain I of the catalytic domain (Hanks et al., 1988). The other intron/exon boundaries are unique, suggesting an ancient divergence of GRK7 from the GRK1, GRK2/3, and GRK4/ $5 / 6$ subfamilies.

The human GRK7 amino acid sequence was compared with those from the pig, ground squirrel, and medaka fish (Oryzias latipes) and with human GRK1 (Fig. 1). Human GRK7 is $85 \%$ identical to pig GRK7 and 59\% identical to GRK7 from the medaka fish at the amino acid level (Table 1). A comparison of GRK7 with the amino acid sequences of other human GRKs demonstrated that GRK7 is closest in homology to GRK1. Human GRK7 is 47,46 , and $43 \%$ identical to human, bovine, and medaka fish GRK1, respectively. Like GRK1, all of the GRK7 proteins contain a CaaX motif that is predicted to code for isoprenylation and carboxymethylation of the $C$ terminus (Clarke, 1992). GRK7 is predicted to be geranylgeranylated, whereas all forms of GRK1, except chicken GRK1 (Zhao et al., 1999), are predicted to be farnesylated. GRK 1 contains two major sites of autophosphorylation at Ser-491 and Thr-492, as well as a minor site at Ser-21
(Palczewski et al., 1992). Of these three sites, only Ser-491 is conserved in GRK7 (Fig. 1) (Ser 490 in HGRK7). The site corresponding to Thr-492 is a glutamic acid residue in GRK7. This region in GRK2 and GRK3 is negatively charged, consisting of an Asp-Glu-Glu-Asp sequence (Benovic et al., 1989, 1991). Previously, we demonstrated that ground squirrel GRK7 could be autophosphorylated (Weiss et al., 1998), although the function of this modification has not been determined. Mutational analysis of the autophosphorylation sites in GRK1 suggests that autophosphorylation may control selectivity of the substrate phosphorylation sites on rhodopsin, the ability to phosphorylate rhodopsin in the dark, and the affinity for ATP (Palczewski et al., 1995). The role of autophosphorylation in the function of GRK7 is the focus of future studies.

\section{Western blot of recombinant GRK7 and GRK1}

To determine the distribution of GRK7 in the retinas of different mammals, two antibodies were generated against synthetic peptides corresponding to amino acids 530-544 and 525-539 near the $\mathrm{C}$ terminus of pig and ground squirrel GRK7, respectively (Fig. 1). This region has little homology with other GRK family members. The antibodies were tested for selective recognition of GRK7 and GRK1 using recombinant proteins expressed in HEK293 cells (Fig. 2). Both antibodies recognize recombinant human, pig, and ground squirrel GRK7. In contrast, neither antibody reacts with human or bovine GRK1. A monoclonal antibody that recognizes the N-terminal half of human GRK1 (D11) (Zhao et al., 1998) detected recombinant human GRK1 in Western blots but did not react with any of the recombinant GRK7 proteins (Fig. 2). Recombinant bovine GRK1 was barely detected by this antibody, probably because of significant differences in sequence within the epitope compared with the human protein. The results demonstrate that these antibodies can discriminate between GRK7 and GRK1 and can be used to determine the expression and cellular location of these kinases in mammalian retinas.

\section{Detection of GRK7 and GRK1 in mammalian retinal extracts}

The expression of GRK7 was examined in extracts from several rod- and cone-dominant mammals by Western blot analysis using the anti-GRK7 and anti-GRK1 antibodies defined in Figure 2. Figure 3 demonstrates that both anti-GRK7 antibodies recognize a band in pig, ground squirrel, chipmunk, bovine, and dog retina extracts corresponding to $62 \mathrm{kDa}$, the estimated molecular size for GRK7. The antibody directed against ground squirrel GRK7 also detected a band of similar size in monkey retina extracts. In contrast, neither antibody detects a protein of the expected molecular size in mouse or rat retina extracts, although the antiground squirrel GRK7 antibody does detect bands $\sim 7 \mathrm{kDa}$ below the predicted molecular size of GRK7. Either GRK7 is not present in these rodents or the sequence is sufficiently different to prevent recognition. Subsequent attempts to clone GRK7 from mouse and rat cDNA and from several mouse genomic libraries were unsuccessful, suggesting that mice (and perhaps rats) may not have the gene for GRK7.

D11, the anti-GRK1 antibody characterized in Figure 2, recognizes a doublet at $\sim 63 \mathrm{kDa}$ in all rod-dominant species except bovine retina. This doublet may be phosphorylated and nonphosphorylated forms of GRK1 or, alternatively, splice variants of the GRK1 gene, GRK1a and GRK1b, first identified in human retinas (Zhao et al., 1998). In those studies, GRK1a was shown to be the more abundant, active form of GRK1. We could not detect GRK1 in bovine, ground squirrel, and chipmunk retinas. This is proba- 


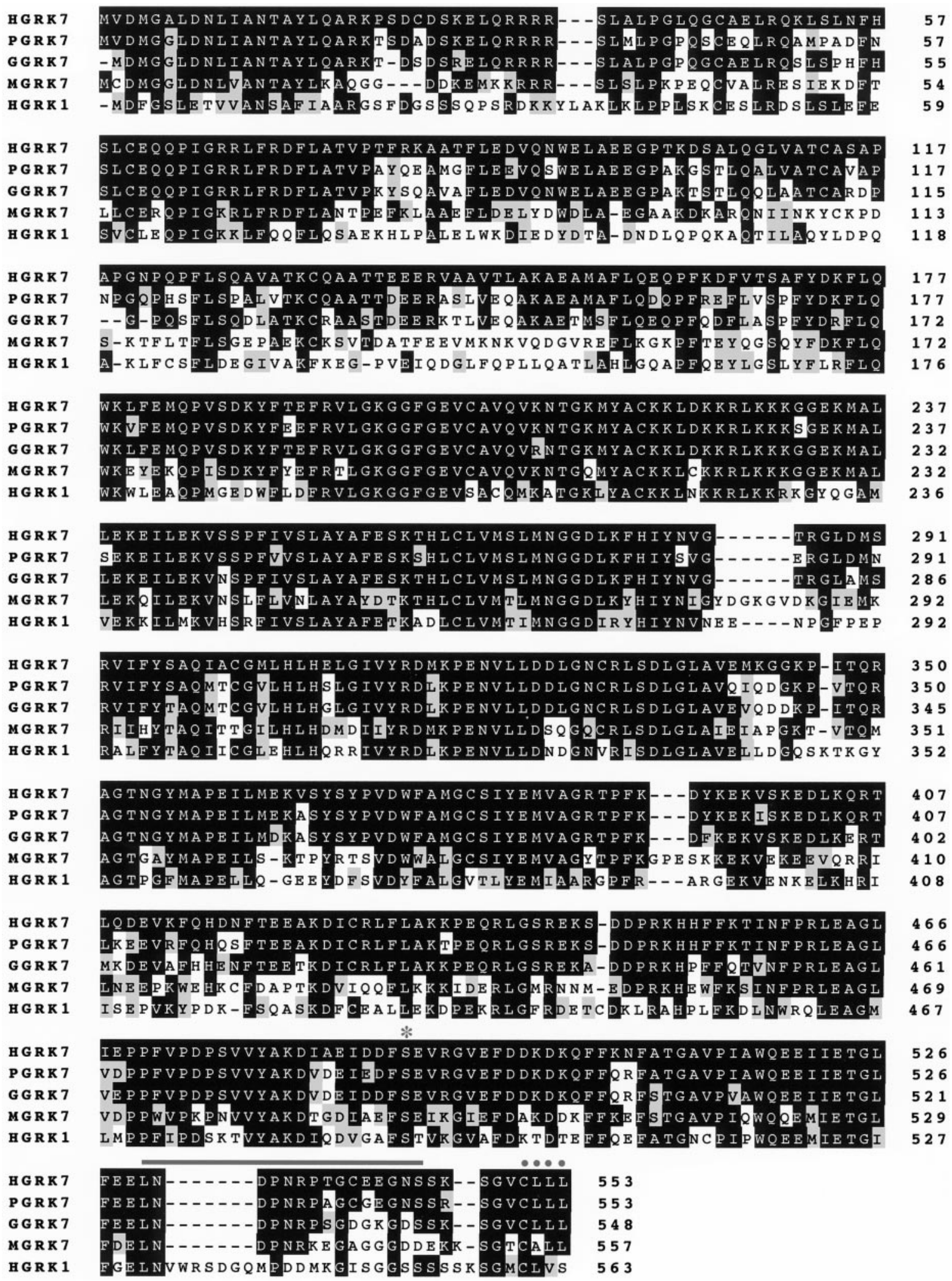

Figure 1. Sequence comparison between human (HGRK7), pig (PGRK7), ground squirrel (GGRK7), medaka (MGRK7) GRK7, and human GRK1 (HGRK1). Areas in black represent amino acid sequence that is identical to human GRK7. Areas in gray represent amino acid sequence that is conserved with human GRK7. The asterisk marks a potential autophosphorylation site in GRK7 and GRK1. The bar (-) marks the peptide sequence in pig and

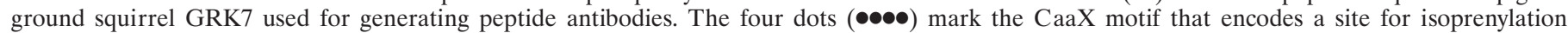
Sequence analysis was performed with the computer program Multiple Sequence Alignment from the Vector NTI software package (InforMax) using the Clustal W algorithm. 


\begin{tabular}{lcc}
\hline Table 1. Sequence identity between human GRK7 and other GRKs \\
& $\begin{array}{l}\text { Amino acid } \\
\text { identity (\%) }\end{array}$ & $\begin{array}{l}\text { Nucleotide } \\
\text { identity (\%) }\end{array}$ \\
\hline GRK7 (human) & 100 & 100 \\
GRK7 (pig) & 85 & 87 \\
GRK7 (GS) & 85 & 84 \\
GRK7 (medaka) & 59 & 62 \\
GRK1 (human) & 47 & 58 \\
GRK1 (bovine) & 46 & 59 \\
GRK1 (medaka) & 43 & 58 \\
GRK2 (human) & 26 & 44 \\
GRK3 (human) & 25 & 42 \\
GRK4 (human) & 45 & 52 \\
GRK5 (human) & 42 & 54 \\
GRK6 (human) & 43 & 56
\end{tabular}

The GenBank accession numbers are as follows: human GRK7, AF282269; pig GRK7, AF282270; ground squirrel GRK7, AF063016; medaka GRK7, AB009568; human GRK1, U63973; bovine GRK1, M73836; medaka GRK1, AB009569; human GRK2, X61157; human GRK3, NM_005160; human GRK4, L03718; human GRK5, NM 005308; human GRK6, L16862. Sequence identities were calculated using the computer program Multiple Sequence Alignment from the Vector NTI software package (InforMax, Bethesda, MD).

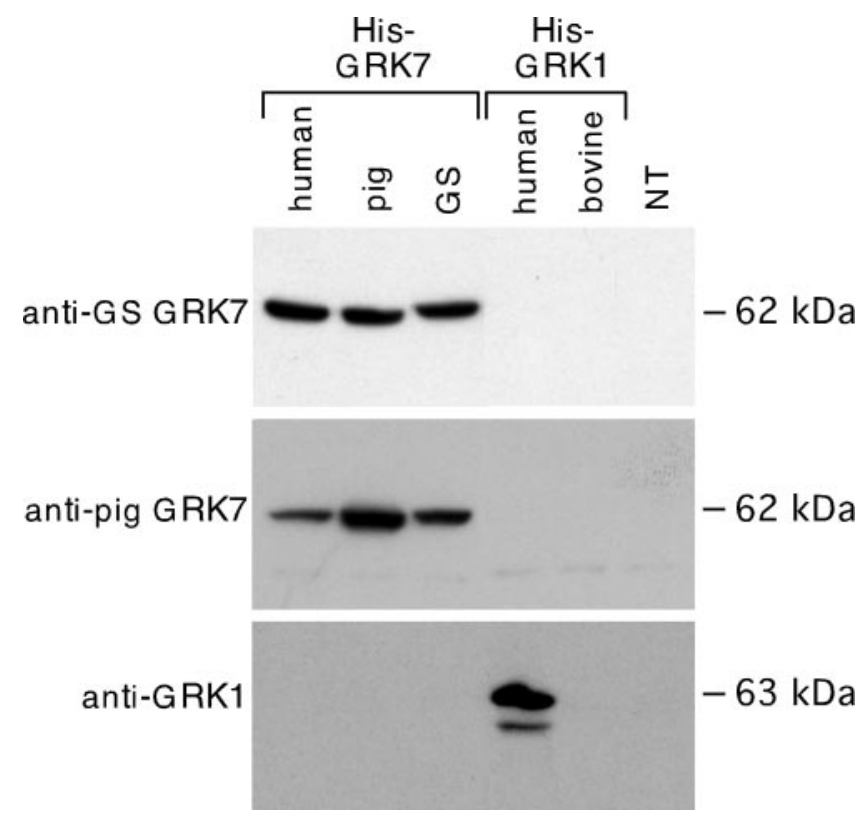

Figure 2. Western blot analysis of recombinant GRK7 and GRK1. Antibodies directed against ground squirrel GRK7 (anti-GS GRK7), pig GRK7 (anti-pig GRK7), and human GRK1 (anti-GRK1) were immunoblotted against extracts from HEK-293 cells expressing recombinant human, pig, and ground squirrel (GS) 6xhistidine-tagged GRK7 (HisGRK7) and human and bovine 6xhistidine-tagged GRK1 (His-GRK1) prepared as described in Materials and Methods. GS, 13-lined ground squirrel; $N T$, nontransfected cell lysates.

bly attributable to a lack of sequence similarity in the epitope rather than the absence of GRK1 in these samples, because GRK1 is abundant in bovine retinas and a fragment of the cDNA has been cloned from ground squirrel retinas (Weiss et al., 1998).

\section{Distribution of GRK7 and GRK1 in cone- and rod-dominant mammals}

\section{Ground squirrel retinas}

Approximately 90-93\% of the photoreceptor cells in the 13-lined ground squirrel retina are classified as cones by morphological

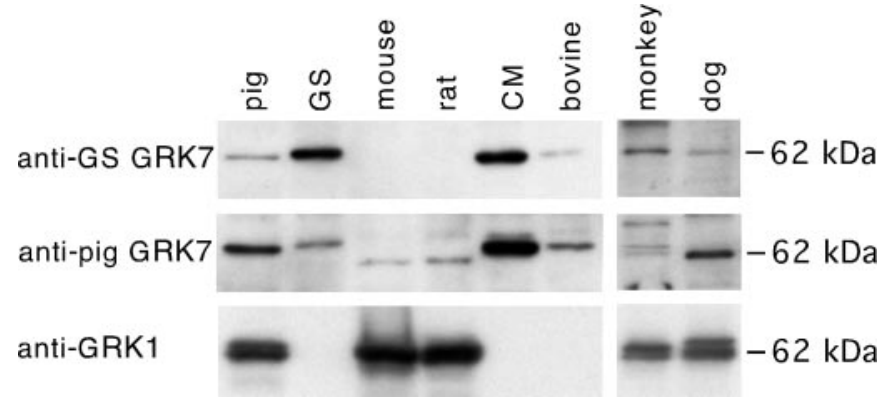

Figure 3. Western blot analysis of retinal extracts for the expression of GRK7 and GRK1. Retinal extracts were prepared from euthanized animals as described in Materials and Methods and analyzed using the anti-GRK7 and anti-GRK1 antibodies characterized in Figure 2. The antibodies were used at dilutions of 1:2000, 1:4000, and 1:10,000 for anti-GS-GRK7, anti-pig GRK7, and anti-GRK1, respectively. GS, 13lined ground squirrel; $C M$, eastern chipmunk.

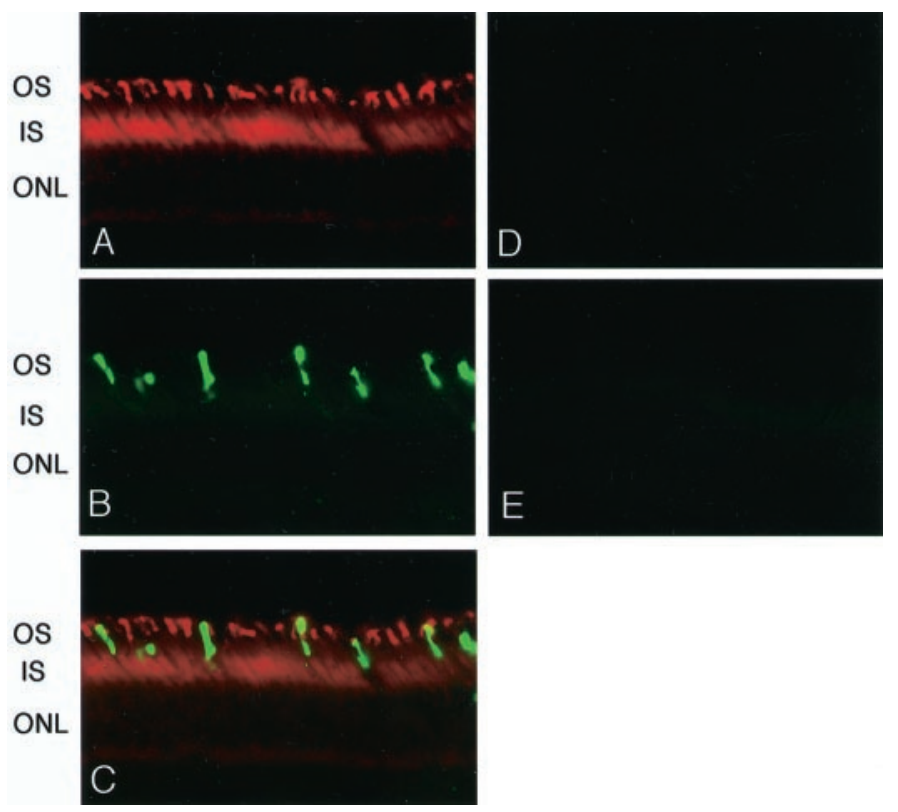

Figure 4. GRK7 expression in the 13-lined ground squirrel retina. Ground squirrel eyes were fixed, enucleated, frozen, and sectioned as described in Materials and Methods. The sections were stained with anti-GS GRK7 $(A)$ or anti-rhodopsin $(B)$ antibodies, both at 1:100 dilution, and visualized with secondary antibodies conjugated to Texas Red or Oregon Green, respectively. An overlay of the two images demonstrates no overlap between GRK7 and rhodopsin staining $(C)$. Control sections were stained in the absence of primary antibody with secondary antibodies conjugated to Texas Red $(D)$ or Oregon Green $(E)$. OS, Photoreceptor cell outer segments; $I S$, photoreceptor cell inner segments; $O N L$, outer nuclear layer.

and biochemical criteria (West and Dowling, 1975; von Schantz et al., 1994). Staining of ground squirrel retina sections with the anti-ground squirrel GRK7 antibody demonstrates that GRK7 is expressed in the majority of the photoreceptor cells and is concentrated in the outer and inner segments (Fig. 4A). In contrast, an antibody directed against rhodopsin stained only a few of the photoreceptors, identifying them as rods (Fig. 4B). An overlay of these two images demonstrates that ground squirrel GRK7 is expressed only in cones and is excluded from the rods expressing rhodopsin (Fig. 4C). Although we have determined that the 

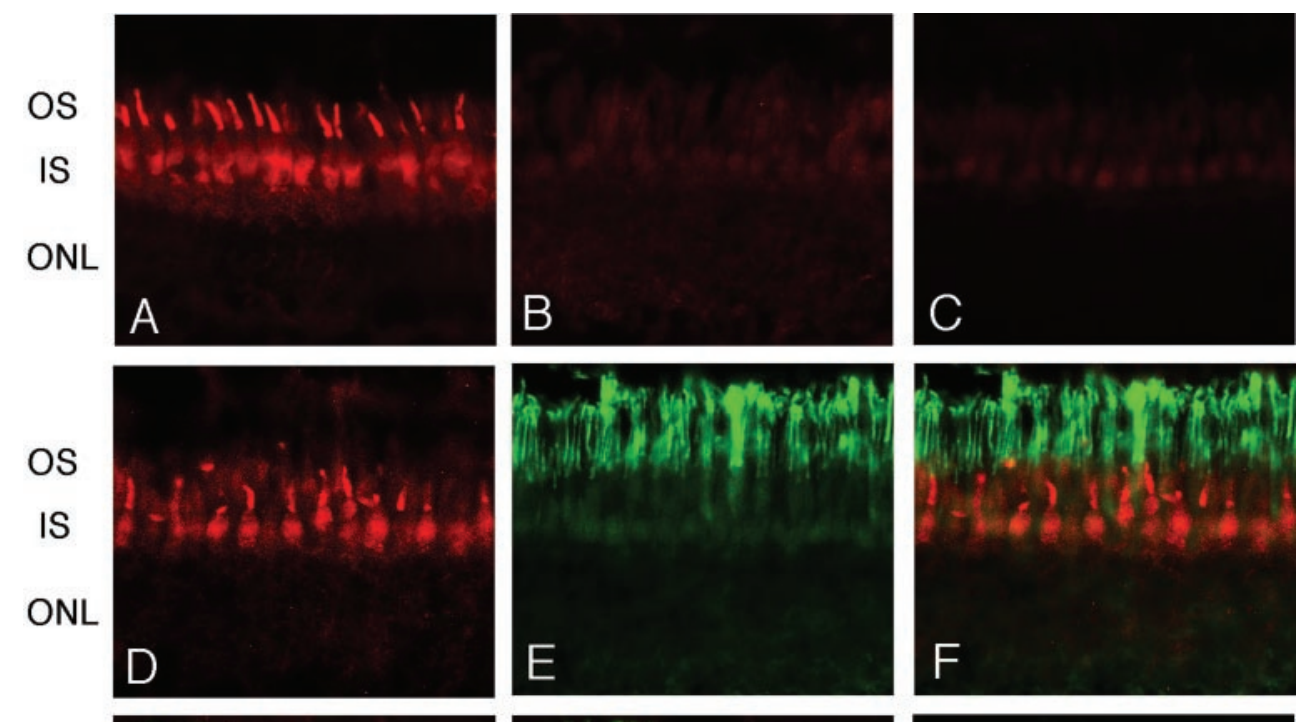

Figure 5. GRK7 and GRK1 expression in the pig retina. Pig eyes were fixed, enucleated, frozen, and sectioned as described in Materials and Methods. The sections were stained with anti-pig GRK7 (1:250 dilution) antibody in the absence $(A)$ or presence $(B)$ of competing peptide corresponding to amino acids 525-539 of the pig GRK7 sequence. Control section (C) stained only with secondary antibody conjugated to Texas Red. A section was double labeled with anti-GRK7 $(D)$ and anti-GRK1 $(E)$ antibodies at 1:250 and 1:5000, respectively. An overlay of these two images $(F)$ demonstrates that GRK7 and GRK1 staining do not overlap. A section $(G)$ double labeled with antiGRK1 (1:500) and red/green opsin (1: 5000) antibodies suggests no expression of GRK1 in red/green cones. A section $(H)$ double labeled with anti-GRK1 (1: $500)$ and blue opsin (1:5000) antibodies demonstrates no expression of GRK1 in blue cones. Control section (I) stained only with Oregon Green-conjugated secondary antibody. Abbreviations are described in the legend to Figure 4.
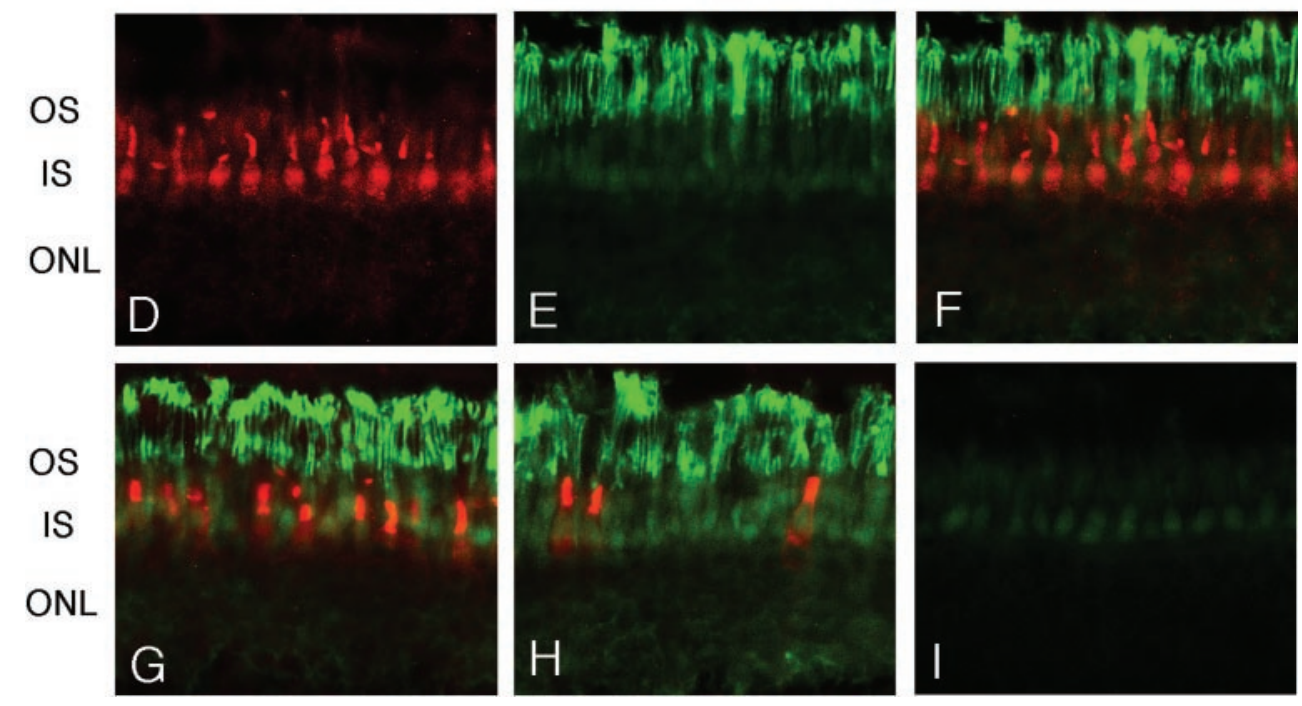

ground squirrel retina expresses GRK1 mRNA (Weiss et al., 1998), we do not have an antibody that recognizes the protein. Therefore, the expression pattern of GRK1 in the ground squirrel was not analyzed.

\section{Pig and dog retinas}

Pigs are rod-dominant mammals that have been used as models for the study of visual signaling. Estimates of the number of cones vary from 5 to $15 \%$ of the photoreceptor cell population in pigs (Prince et al., 1960; Gerke et al., 1995), whereas human retinas contain $\sim 5-6 \%$ cones (Oyster, 1999). Because its size and rod/ cone ratio are similar to the human eye, the pig eye has become an important model for retinal diseases such as retinitis pigmentosa (Petters et al., 1997; Li et al., 1998). Pig retina sections were stained with anti-pig GRK7 and anti-GRK1 antibodies (Fig. 5). GRK7 staining was most intense in the outer and inner segments of cones (Fig. $5 A$ ), similar to the pattern in the ground squirrel retina (Fig. 4A). To determine the specificity of the staining for GRK7, the antibody was preabsorbed with a synthetic peptide corresponding to amino acids 530-544 of pig GRK7 before incubation with pig retinal sections. As seen in Figure $5 B$, this treatment reduces cone-specific staining to levels that are comparable with the amount of staining in the absence of primary antibody (Fig. 5C). Double-label experiments were performed to determine whether GRK7 and GRK1 are coexpressed in the same photoreceptor cells (Fig. 5D-F). In contrast to GRK7, which seems to be expressed only in cones (Fig. $5 A, D$ ), GRK1 appears to be expressed only in rods in the pig retina (Fig. $5 E$ ), a result confirmed by overlay of the two images (Fig. $5 F$ ). To confirm our observations regarding the distribution of GRK1, pig sections were double labeled with anti-GRK1 antibody and anti-cone opsin antibodies that recognize red/green cones (Fig. $5 G$ ) or blue cones (Fig. $5 H$ ). These overlay images show that the GRK1 is not expressed in the cones of pig retinas. Dogs are also rod-dominant mammals that have been used extensively as models for the study of cone-specific and rod-cone degenerative diseases (Acland et al., 1998; Akhmedov et al., 1998). In dog retinas, GRK7 appears to be expressed in cones (Fig. 6A), and GRK1 appears to be expressed in rods (Fig. $6 B$ ). An overlay of the images detects no overlap in staining (Fig. 6C), similar to the results described above for pig retinas.

\section{Primate retinas}

The retina of the rhesus monkey is similar to the human retina in its organization, visual acuity, and possession of trichromatic color vision (Wikler and Rakic, 1996). Although these animals have fewer photoreceptor cells (63 million compared with 95 million in humans), they have very similar $\mathrm{rod} / \mathrm{cone}$ ratios. In rhesus monkeys, GRK7 appears to be highly expressed in cones (Fig. 7A); however, GRK1 is expressed in both rods and cones (Fig. $7 B$ ). An overlay of the images (Fig. 7C) demonstrates that GRK7 and GRK1 have similar distributions in the outer and inner segments in cones, raising the possibility that both of these kinases participate in the visual signaling pathway in cones.

Human retina sections were also examined for GRK7 expression using the ground squirrel GRK7 antibody (Fig. 8, top panel). Immunoreactivity was observed in cone cells, similar to that seen in the retinas of rhesus monkeys (Fig. 7A). The staining was particularly intense in the outer segments. To confirm that this staining is specific for GRK7, the antibody was preabsorbed with either the ground squirrel peptide (amino acids 525-539) (Fig. 8, middle panel) or a peptide corresponding to the human GRK7 sequence (amino acids 530-544) (Fig. 8, bottom panel). Both peptides eliminated detectable binding of the anti-GRK7 antibody to human retina sections. In contrast, GRK1 immunoreactive product was localized to both rods and cones (data not 

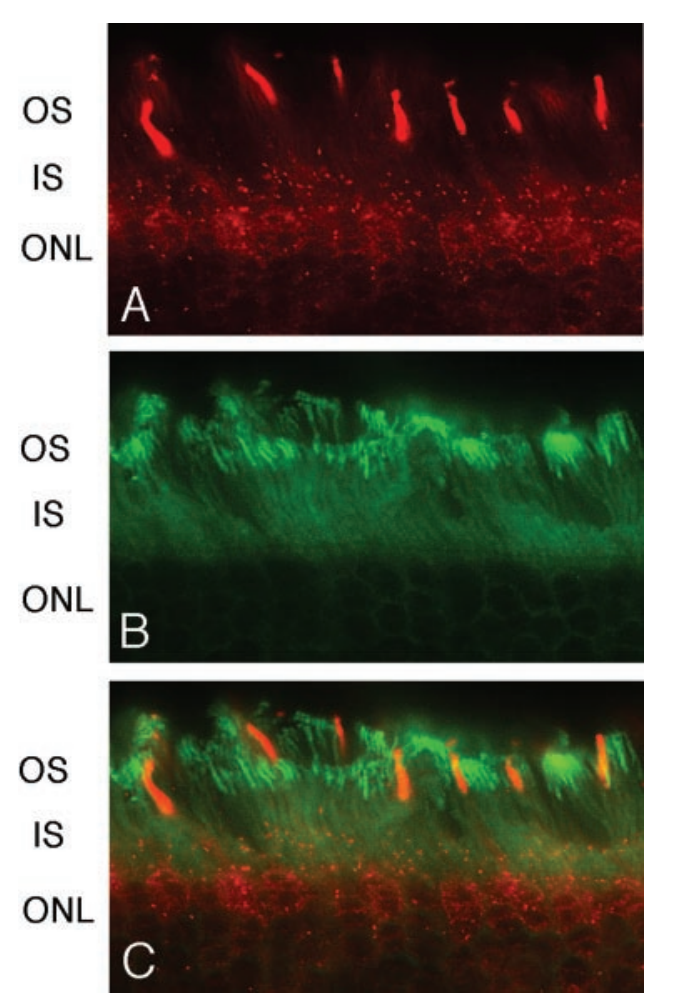

Figure 6. GRK7 and GRK1 expression in the dog retina. Dog eyes were fixed, enucleated, frozen, and sectioned as described in Materials and Methods. Sections were double labeled with the anti-pig GRK7 antibody $(A)$ and anti-GRK1 $(B)$ at 1:250 and 1:5000 dilutions, respectively. An overlay of these two images $(C)$ demonstrates no overlap between the expression patterns of the two kinases. Control sections were stained only with secondary antibodies conjugated to Texas Red and Oregon Green (data not shown). Abbreviations are described in the legend to Figure 4.

shown), as described previously (Zhao et al., 1998). Therefore, in both monkey and human retinas, GRK7 and GRK1 are coexpressed in cones.

\section{Mice and rats}

The ability to generate transgenic and knock-out mice targeting specific genes has been useful for elucidating the importance of a number of proteins in visual signaling. Therefore, attempts were made to localize GRK7 in the retinas of both mice and rats; however, no staining was detected using either GRK7 antibody (data not shown), consistent with no detectable GRK7 immunoreactivity by Western blot analysis (Fig. 3) and with our inability to clone GRK7 from mouse cDNA or genomic libraries, despite extensive efforts. Furthermore, the staining of mouse retinas with the anti-GRK1 antibody demonstrated that GRK1 is expressed in both rods and cones (data not shown), as described previously (Lyubarsky et al., 2000).

\section{The expression of GRK7 in red/green and blue cones}

Pig retina sections were double labeled with anti-pig GRK7 (Fig. $9 A, D)$ and monoclonal antibodies against either red/green (Fig. $9 B$ ) or blue (Fig. 9E) cones to determine whether GRK7 is expressed in all populations of cones. GRK7 is detected in all cones labeled with either cone opsin antibody and is highly concentrated in both the inner and outer segments, whereas the cone opsins appear to be restricted to the outer segments of both red/green and blue cones. Overlay of these images (Fig. 9C,F) demonstrates that the distribution of GRK7 and the cone opsins in the cone cells overlap in the outer segments. Similar results were observed in dog and monkey retinas (data not shown), indicating that GRK7 is expressed in all populations of cones in these rod-dominant mammals.

\section{DISCUSSION}

The active, meta II form of the cone opsins decays more rapidly than metarhodopsin II in rods (Shichida et al., 1994; Imai et al., 1995; Imai et al., 1997), suggesting that the decay of the cone opsins may contribute to the rapid turnoff of visual signaling in cone cells (Cideciyan et al., 1998; Shichida and Imai, 1998). Cone opsin phosphorylation has been demonstrated in lower vertebrates (Walter et al., 1986), and distinct arrestins have been identified in the cones of mammals and lower vertebrates $(\mathrm{Mu}$ rakami et al., 1993; Craft et al., 1994; Maeda et al., 2000; Smith et al., 2000). In addition, GRK1 is expressed in some mammalian cones and GRK1-/- mice exhibit slowed cone cell recovery (Lyubarsky et al., 2000). These observations provide support for the idea that phosphorylation and arrestin binding also play a role in opsin desensitization in cones. The present study was designed to determine whether GRK7, a novel GRK expressed in cones in lower vertebrates and cone-dominant mammals, is expressed in the retinas of rod-dominant mammals and to compare its cellular location with GRK1. We have successfully cloned GRK7 from pig

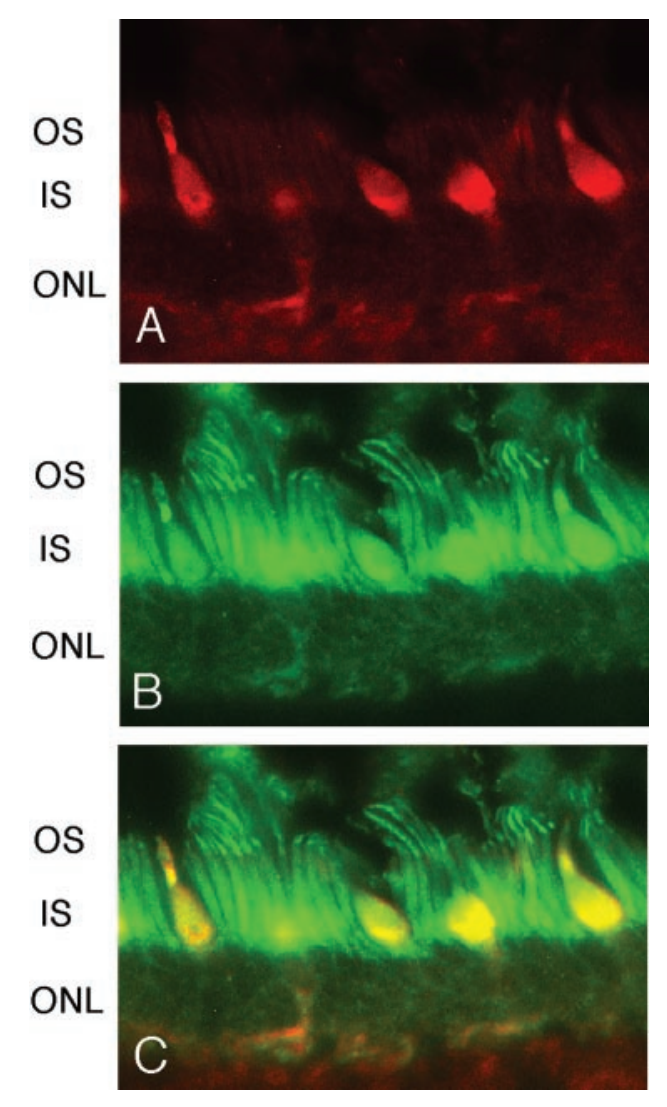

Figure 7. GRK7 and GRK1 expression in the rhesus monkey retina. Monkey eyes were fixed, enucleated, frozen, and sectioned as described in Materials and Methods. Sections were double labeled with the anti-GS GRK7 antibody $(A)$ and anti-GRK1 $(B)$ at 1:100 and 1:1000 dilutions, respectively. An overlay of the two images $(C)$ demonstrates that GRK7 and GRK1 are coexpressed in monkey cones. Control sections were stained only with secondary antibodies conjugated to Texas Red and Oregon Green (data not shown). Abbreviations are described in the legend to Figure 4. 


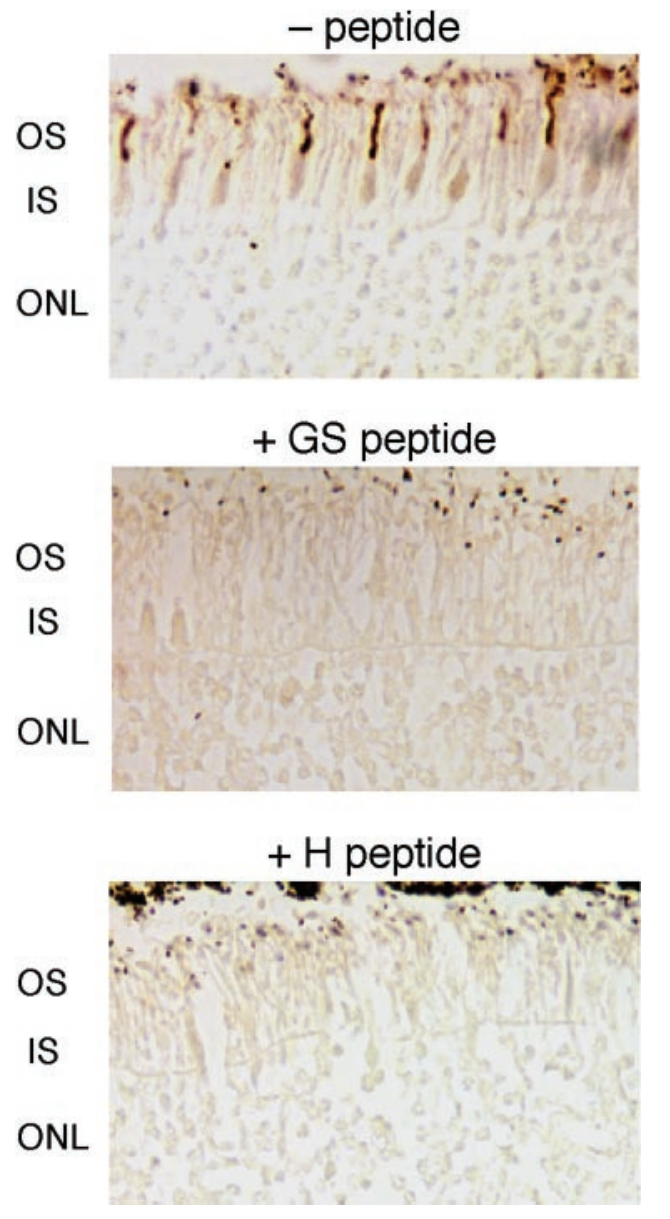

Figure 8. GRK7 expression in the human retina. Human retinas were prepared as described in Materials and Methods and stained with the anti-GS GRK7 antibody (1:500 dilution) in the absence (-peptide) (top panel) or presence of peptides corresponding to amino acids 525-539 of the ground squirrel sequence (+ GS peptide) (middle panel) or amino acids 529-543 of the human sequence ( $+H$ peptide) (bottom panel). Abbreviations are described in the legend to Figure 4.

and human retinas and have shown for several rod-dominant mammals that the expression of this newest GRK family member is concentrated in cone outer and inner segments. We have also shown that both red/green and blue cones express GRK7. The coexpression of GRK7 and GRK1 in monkey and human cone photoreceptor cells indicates that both kinases could play a role in cone opsin desensitization in primates.

An alignment of the predicted protein sequences suggests that GRK7 is geranylgeranylated, on the basis of the CaaX motif at the $\mathrm{C}$ terminus. In contrast, GRK1, with the exception of chicken, is farnesylated, as would be predicted from its CaaX motif, in both in vivo and in vitro studies (Anant and Fung, 1992; Z hao et al., 1999). Previous experiments have indicated that isoprenylation is required for full activity of GRK1 (Inglese et al., 1992a,b). An exchange of the $\mathrm{CaaX}$ motif in GRK1 from farnesylation to geranylgeranylation alters the light-dependent association of the kinase with the membrane (Inglese et al., 1992a). The binding of the farnesylated protein to the membrane is light-dependent, whereas the geranylgeranylated protein is associated with the membrane in both dark and light-exposed conditions. From these results, we predict that GRK7 will be closely associated with the membrane in both dark and light conditions, which may increase
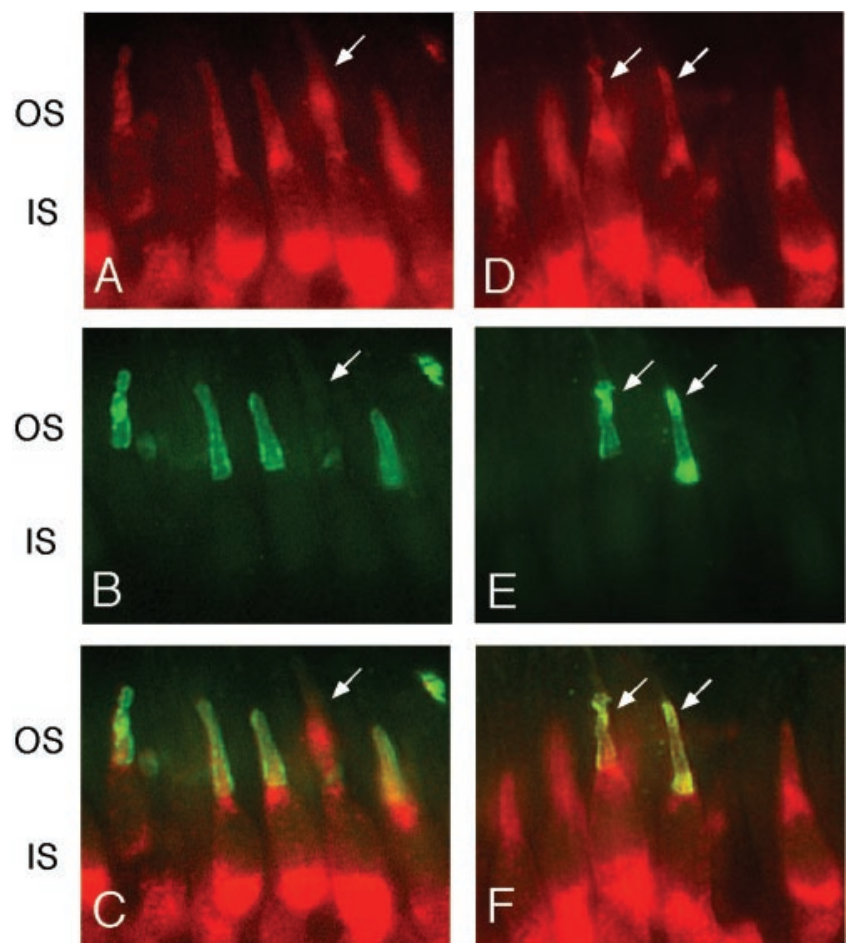

Figure 9. Expression of GRK7 in red/green and blue cones in the pig retina. Pig retinas prepared as described in the legend to Figure 5 were stained with anti-pig GRK7 $(A, D)$ and either COS-1 $(B)$ antibody that recognizes red/green opsin or OS-2 $(E)$, an antibody that recognizes blue opsin. An overlay of the images demonstrates that GRK7 is expressed in red/green cones $(C)$ and blue cones $(F)$. All white arrows point to blue cones. Abbreviations are described in the legend to Figure 4.

the rate of phosphorylation compared with GRK1 and lead to more rapid desensitization. Conceivably, such differences in the kinetics of phosphorylation could contribute to the more rapid rate of signal turnoff observed for cones in physiological experiments. Other factors may also influence the rates of desensitization of the cone opsins. For example, the calcium sensor protein, recoverin, has been shown to block the function of GRK1 in vitro. Calmodulin has also been shown to influence the activity of other GRKs (Pitcher et al., 1998; Burgoyne and Weiss, 2001). The identification of potential binding partners for GRK7 and their influence on its substrate specificity and catalytic activity are areas of ongoing research in our laboratory.

Distinct but related proteins generated by gene duplication appear to play parallel roles in visual signaling in rods and cones. The expression of both rod- and cone-specific opsins, transducins, and visual arrestins is tightly regulated in the retina (Grunwald et al., 1986; Szél et al., 1986, 1988; Lerea et al., 1989; Craft et al., 1994; Sakuma et al., 1996). However, other proteins, such as the GCAPs, show more complex expression patterns. GCAP1 has been localized to both rods and cones in bovine and mouse retinas (Gorczyca et al., 1995; Howes et al., 1998), whereas the expression of GCAP2 in rods and cones varies, depending on the species (Dizhoor et al., 1995; Otto-Bruc et al., 1997; Howes et al., 1998). Our results indicate that GRK7 and GRK1 have a similarly complex pattern of expression. GRK1, the rod cell GRK, has been identified in the cones of human (Zhao et al., 1998), monkey (Sears et al., 2000), and mouse (Lyubarsky et al., 2000) retinas. Our experiments confirm this localization, using antibodies that we have determined do not cross-react with GRK7. However, we 
have shown that the expression of GRK1 in cones is speciesspecific; we were unable to detect GRK1 in the cones of dog and pig retinas. GRK1 is also expressed exclusively in rods in the medaka fish (Hisatomi et al., 1998). In contrast, GRK7 is concentrated in cones in both cone- and rod-dominant mammals (Figs. 4-9) and in fish (Hisatomi et al., 1998). An intriguing exception is the absence of detectable levels of GRK7 in mouse and rat retinas, despite the ability of our antibodies to recognize this kinase in various other mammals. We were also unable to detect the GRK7 sequence in mouse or rat cDNA or mouse genomic libraries using probes from multiple domains of GRK7. Although we cannot entirely rule out the possibility that sequence divergence has prevented us from detecting GRK7 in the genomes of these two rodents, our results suggest that mice and rats, which have very few cones, may have lost the gene for GRK7 at some time during their evolution. Interestingly, GCAP3 also appears to be absent from mice and rats (Haeseleer et al., 1999), suggesting that other visual signaling proteins may not be expressed in all mammalian species. The coexpression of GRK7 and GRK1 in humans and monkeys, but not in pigs, dogs, or lower vertebrates, is intriguing from an evolutionary standpoint. Whether these primates gained the ability to express both kinases or the other species lost the expression of GRK1 in cones is difficult to determine. An analysis of GRK expression patterns in retinas from a broad array of species may help to resolve this issue.

The absence of detectable levels of GRK7 in mice and rats, as well as the expression of GRK1 in the cones of some mammalian species but not others, also illustrates the problem of selecting a mammalian model for the study of human cone vision. For example, a recent report (Cideciyan et al., 1998) characterized cone signaling in patients with a form of Oguchi's disease resulting from inactivating mutations in GRK1 (Yamamoto et al., 1997). These patients experience night blindness caused by the inability of rods to recover sensitivity after light exposure (Carr and Gouras, 1965; Carr and Ripps, 1967). GRK1 mutations identified in patients result in reduced ability to phosphorylate rhodopsin (Khani et al., 1998), suggesting that a defect in rhodopsin desensitization is responsible for the pathophysiology of the disease. Electroretinograms also revealed a mild defect in cone recovery; however, GRK1-/- mice exhibit a more severe defect in recovery of cone signaling than the human patients (Lyubarsky et al., 2000). As a control for indirect effects on cone recovery, mice with a deletion of rod arrestin (which is not expressed in cones) were also examined (Xu et al., 1997; Lyubarsky et al., 2000). These mice do not exhibit defects in cone recovery, although they show delayed rod recovery similar to the GRK1-/- mice. These results indicate that desensitization in cones may be controlled differently in mice and humans. In the present report we have shown in monkey retinas that GRK7 and GRK1 colocalize in the inner and outer segments of cone photoreceptors and that GRK7 colocalizes with the cone opsins in the outer segments. Therefore, the expression of GRK7 in human cones may partly compensate for the loss of GRK1 in patients with the GRK1 form of Oguchi's disease. If that is the case, elucidation of the relative roles of GRK7 and GRK1 in desensitization will be of major importance in understanding human cone visual signaling.

\section{REFERENCES}

Acland GM, Ray K, Mellersh CS, Gu W, Langston A, Rine J, Ostrander EA, Aguirre GD (1998) Linkage analysis and comparative mapping of canine progressive rod-cone degeneration ( $p r c d$ ) establishes potential locus homology with retinitis pigmentosa (RP17) in humans. Proc Natl Acad Sci USA 95:3048-3053.

Akhmedov NB, Piriev NI, Pearce-Kelling S, Acland GM, Aguirre GD, Farber DB (1998) Canine cone transducin- $\gamma$ gene and cone degeneration in the $c d$ dog. Invest Ophthalmol Vis Sci 39:1775-1781.

Anant JS, Fung BK-K (1992) In vivo farnesylation of rat rhodopsin kinase. Biochem Biophys Res Commun 183:468-473.

Baylor DA (1987) Photoreceptor signals and vision. The Proctor lecture. Invest Ophthalmol Vis Sci 28:34-49.

Benovic JL, DeBlasi A, Stone WC, Caron MG, Lefkowitz RJ (1989) Beta-adrenergic receptor kinase: primary structure delineates a multigene family. Science 246:235-240.

Benovic JL, Onorato JJ, Arriza JL, Stone WC, Lohse M, Jenkins NA, Gilbert DJ, Copeland NG, Caron MG, Lefkowitz RJ (1991) Cloning, expression, and chromosomal localization of beta-adrenergic receptor kinase 2. A new member of the receptor kinase family. J Biol Chem 266:14939-14946.

Burgoyne RD, Weiss JL (2001) The neuronal calcium sensor family of $\mathrm{Ca}^{2+}$-binding proteins. Biochem J 353:1-12.

Carr RE, Gouras P (1965) Oguchi's disease. Arch Ophthalmol 73:646-656.

Carr RE, Ripps H (1967) Rhodopsin kinetics and rod adaptation in Oguchi's disease. Invest Ophthalmol Vis Sci 6:426-436.

Cideciyan AV, Zhao X, Nielsen L, Khani SC, Jacobson SG, Palczewski K (1998) Null mutation in the rhodopsin kinase gene slows recovery kinetics of rod and cone phototransduction in man. Proc Natl Acad Sci USA 95:328-333.

Clarke S (1992) Protein isoprenylation and methylation at carboxylterminal cysteine residues. Annu Rev Biochem 61:355-386.

Craft CM, Whitmore DH, Wiechmann AF (1994) Cone arrestin identified by targeting expression of a functional family. J Biol Chem 269:4613-4619.

Dizhoor AM, Olshevskaya EV, Henzel WJ, Wong SC, Stults JT, Ankoudinova I, Hurley JB (1995) Cloning, sequencing, and expression of a $24-\mathrm{kDa} \mathrm{Ca}^{2+}$-binding protein activating photoreceptor guanylyl cyclase. J Biol Chem 270:25200-25206.

Fain GL, Matthews HR, Cornwall MC, Koutalos Y (2001) Adaptation in vertebrate photoreceptors. Physiol Rev 81:117-151.

Gerke CG, Hao Y, Wong F (1995) Topography of rods and cones in the retina of the domestic pig. Hong Kong Med J 1:302-308.

Gorczyca WA, Polans AS, Surgucheva IG, Subbaraya I, Baehr W, Palczewski K (1995) Guanylyl cyclase activating protein. A calcium-sensitive regulator of phototransduction. J Biol Chem 270:22029-22036.

Grunwald GB, Gierschik P, Nirenberg M, Spiegel A (1986) Detection of $\alpha$-transducin in retinal rods but not cones. Science 231:856-859.

Haeseleer F, Sokal I, Li N, Pettenati M, Rao N, Bronson D, Wechter R, Baehr W, Palczewski K (1999) Molecular characterization of a third member of the guanylyl cyclase-activating protein subfamily. J Biol Chem 274:6526-6535.

Hanks SK, Quinn AM, Hunter T (1988) The protein kinase family: conserved features and deduced phylogeny of the catalytic domains. Science 241:42-52.

Hisatomi O, Matsuda S, Satoh T, Kotaka S, Imanishi Y, Tokunaga F (1998) A novel subtype of G-protein-coupled receptor kinase, GRK7, in teleost cone photoreceptors. FEBS Lett 424:159-164.

Howes K, Bronson JD, Dang YL, Li N, Z hang K, Ruiz C, Helekar B, Lee M, Subbaraya I, Kolb H, Chen J, Baehr W' (1998) Gene array and expression of mouse retina guanylate cyclase activating proteins 1 and 2. Invest Ophthalmol Vis Sci 39:867-875.

Imai H, Imamoto Y, Yoshizawa T, Shichida Y (1995) Difference in molecular properties between chicken green and rhodopsin as related to the functional difference between cone and rod photoreceptor cells. Biochemistry 34:10525-10531.

Imai H, Terakita A, Tachibanaki S, Imamoto Y, Yoshizawa T, Shichida Y (1997) Photochemical and biochemical properties of chicken bluesensitive cone visual pigment. Biochemistry 36:12773-12779.

Inglese J, Koch WJ, Caron MG, Lefkowitz RJ (1992a) Isoprenylation in regulation of signal transduction by G-protein-coupled receptor kinases. Nature 359:147-150.

Inglese J, Glickman JF, Lorenz W, Caron MG, Lefkowitz RJ (1992b) Isoprenylation of a protein kinase. J Biol Chem 267:1422-1425.

Khani SC, Abitbol M, Yamamoto S, Maravic-Magovcevic I, Dryja TP (1996) Characterization and chromosomal localization of the gene for human rhodopsin kinase. Genomics 35:571-576.

Khani SC, Nielsen L, Vogt TM (1998) Biochemical evidence for pathogenicity of rhodopsin kinase mutations correlated with the Oguchi form of congenital stationary night blindness. Proc Natl Acad Sci USA 95:2824-2827.

Krupnick JG, Benovic JL (1998) The role of receptor kinases and arrestins in G protein-coupled receptor regulation. Annu Rev Pharmacol Toxicol 38:289-319.

Lerea CL, Bunt-Milam AH, Hurley JB (1989) $\alpha$ transducin is present in blue-, green-, and red-sensitive cone photoreceptors in the human retina. Neuron 3:367-376. 
Li ZY, Wong F, Chang JH, Possin DE, Hao Y, Petters RM, Milam AH (1998) Rhodopsin transgenic pigs as a model for human retinitis pigmentosa. Invest Ophthalmol Vis Sci 39:808-819.

Lyubarsky AL, Chen C-K, Simon MI, Pugh EN (2000) Mice lacking G-protein receptor kinase 1 have profoundly slowed recovery of conedriven retinal responses. J Neurosci 20:2209-2217.

Maeda T, Ohguro H, Sohma H, Kuroki Y, Wada H, Okisaka S, Murakami A (2000) Purification and characterization of bovine cone arrestin (cArr). FEBS Lett 470:336-340.

Murakami A, Yajima T, Sakuma H, McLaren MJ, Inana G (1993) $\mathrm{X}$-arrestin: a new retinal arrestin mapping to the $\mathrm{X}$ chromosome. FEBS Lett 334:203-209.

Otto-Bruc A, Fariss RN, Haeseleer F, Huang J, Buczylko J, Surgucheva I, Baehr W, Milam AH, Palczewski K (1997) Localization of guanylate cyclase-activating protein 2 in mammalian retinas. Proc Natl Acad Sci USA 94:4727-4732.

Oyster CW (1999) The human eye: structure and function. Sunderland, MA: Sinauer.

Palczewski K, Buczylko J, Van Hooser P, Carr SA, Huddleston MJ, Crabb JW (1992) Identification of the autophosphorylation sites in rhodopsin kinase. J Biol Chem 267:18991-18998.

Palczewski K, Ohguro H, Premont RT, Inglese J (1995) Rhodopsin kinase autophosphorylation: characterization of site-specific mutations. J Biol Chem 270:15294-15298.

Penn RB, Benovic JL (1994) Structure of the human gene encoding the $\beta$-adrenergic receptor kinase. J Biol Chem 269:14924-14930.

Petters RM, Alexander CA, Wells KD, Collins EB, Sommer JR, Blanton MR, Rojas G, Hao Y, Flowers WL, Banin E, Cideciyan AV, Jacobson SG, Wong F (1997) Genetically engineered large animal model for studying cone photoreceptor survival and degeneration in retinitis pigmentosa. Nat Biotechnol 15:965-970.

Pitcher JA, Freedman NJ, Lefkowitz RJ (1998) G protein-coupled receptor kinases. Annu Rev Biochem 67:653-692.

Premont RT, Macrae AD, Stoffel RH, Chung N, Pitcher JA, Ambrose C, Inglese J, MacDonald ME, Lefkowitz RJ (1996) Characterization of the $\mathrm{G}$ protein-coupled receptor kinase GRK4. Identification of four splice variants. J Biol Chem 271:6403-6410.

Premont RT, Macrae AD, Aparicio SAJR, Kendall HE, Welch JE, Lefkowitz RJ (1999) The GRK4 subfamily of G protein-coupled receptor kinases. Alternative splicing, gene organization and sequence conservation. J Biol Chem 274:29381-29389.

Prince JH, Diesem CD, Eglitis I, Ruskell GL (1960) The pig. In: Anatomy and histology of the eye and orbit in domestic animals, pp 210-233. Springfield, IL: Charles C. Thomas.

Sakuma H, Inana G, Murakami A, Higashide T, McLaren MJ (1996) Immunolocalization of $\mathrm{X}$-arrestin in human cone photoreceptors. FEBS Lett 382:105-110.

Sears S, Erickson A, Hendrickson A (2000) The spatial and temporal expression of outer segment proteins during development of Macaca monkey cones. Invest Ophthalmol Vis Sci 41:971-979.
Shichida Y, Imai H (1998) Visual pigment: G-protein-coupled receptor for light signals. Cell Mol Life Sci 54:1299-1315.

Shichida Y, Imai H, Imamoto Y, Fukada Y, Yoshizawa T (1994) Is chicken green-sensitive cone visual pigment a rhodopsin-like pigment? A comparative study of the molecular properties between chicken green and rhodopsin. Biochemistry 33:9040-9044.

Smith WC, Gurevich EV, Dugger DR, Vishnivetskiy SA, Shelamer CL, McDowell JH, Gurevich V V (2000) Cloning and functional characterization of salamander rod and cone arrestins. Invest Ophthalmol Vis Sci 41:2445-2455.

Szél A, Takacs L, Monostori E, Diamantstein T, Vigh-Teichmann I, Rohlich P (1986) Monoclonal antibody-recognizing cone visual pigment. Exp Eye Res 43:871-883.

Szél A, Diamantstein T, Röhlich P (1988) Identification of the bluesensitive cones in the mammalian retina by anti-visual pigment antibody. J Comp Neurol 273:593-602.

von Schantz M, Szél A, van Veen T, Farber DB (1994) Expression of phototransduction cascade genes in the ground squirrel retina. Invest Ophthalmol Vis Sci 35:2558-2566.

Walter AE, Shuster TA, Farber DB (1986) Light-induced phosphorylation of proteins from the all-cone retina of the lizard, Anolis carolinensis. Invest Ophthalmol Vis Sci 27:1609-1614.

Weiss ER, Raman D, Shirakawa S, Ducceschi MH, Bertram PT, Wong F, Kraft TW, Osawa S (1998) The cloning of GRK7, a candidate cone opsin kinase, from cone- and rod-dominant mammalian retinas. Mol Vis 4:27.<http://www.molvis.org/molvis/v4/p27>.

West RW, Dowling JE (1975) Anatomical evidence for cone and rodlike receptors in the gray squirrel, ground squirrel and prairie dog retinas. J Comp Neurol 159:439-460.

Wikler KC, Rakic P (1996) Development of photoreceptor mosaics in the primate retina. Perspect Dev Neurobiol 3:161-175.

Xu J, Dodd RL, Makino CL, Simon MI, Baylor DA, Chen J (1997) Prolonged photoresponses in transgenic mouse rods lacking arrestin. Nature 389:505-509.

Yamamoto S, Sippel KC, Berson EL, Dryja TP (1997) Defects in the rhodopsin kinase gene in the Oguchi form of stationary night blindness. Nat Genet 15:175-178.

Yau KW (1994) Phototransduction mechanism in retinal rods and cones. The Friedenwald lecture. Invest Ophthalmol Vis Sci 35:9-32.

Zhang Y, Li A, Zhu X, Wong CH, Brown B, Craft CM (2001) Cone arrestin expression and induction in retinoblastoma cells. In: Retinal degeneration diseases and experimental therapy (Hollyfield J, La Vail M, Anderson G, eds). New York: Kluwer Academic/Plenum, in press.

Zhao X, Yokoyama K, Whitten ME, Huang J, Gelb MH, Palzcewski K (1999) A novel form of rhodopsin kinase from chicken retina and pineal gland. FEBS Lett 454:115-121.

Zhao XY, Huang J, Khani SC, Palczewski K (1998) Molecular forms of human rhodopsin kinase (GRK1). J Biol Chem 273:5124-5131.

Zhu X, Craft CM (2000) Modulation of CRX transactivation activity by phosducin isoforms. Mol Cell Biol 20:5216-5226. 